\title{
GELANG PENDETEKSI KEBERADAAN ANAK DAN MENGGUNAKAN TOMBOL DARURAT
}

\author{
Fery Setyo Aji', Fery Andriawan Amrin², Muhammad Dzuljalali Wal Ikram³, \\ Lilis Nur Hayati ${ }^{4}$ \\ 17ferysetyoaji@gmail.com, 2feryandriawanamrin002@gmail.com, ${ }^{3}$ mdzuljalaliw@gmail.com, \\ ${ }^{4}$ lilis.nurhayati@umi.ac.id \\ 1,2,3,4 Universitas Muslim Indonesia
}

\begin{abstract}
Abstrak
Perkembangan Zaman semakin meningkat dengan banyaknya kasus-kasus Penculikan anak akhir-akhir ini dan cukup meresahkan masyakarakat khususnya orangtua yang memiliki anak yang umurnya rata-rata 7-12 tahun dan jenjang SD/MI. Pada saat ajaran baru yaitu masuk sekolah. Anak yang mulai sekolah sudah diluar pantuan orangtua sehingga tingkat penculikan anak bisa saja terjadi membuka peluang oknum untuk melakukan tindakan kriminal. Berdasarkan hal tersebut, maka dapat disimpulkan perlunya membangun perangkat lunak yang dapat membantu permasalahan para orangtua dan anak yang sudah di paparkan sebelumnya. Perancangan Sistem Ge-Tekbol Pendeteksi keberadaan anak dengan smartphone orangtua yang terpasang aplikasi Android dan anak dapat mengeriminkan sms notifikasi darurat saat keadaan terdesak kepada orangtua dengan menekan tombol. Ge-Tekbol menggunakan teknologi Assisted Global Positioning System (A-GPS), penentu posisi pada GPS dengan bantuan server pembantu dari BTS seluler.Perangkat lunak yang dibangun menggunakan pemodelan berbasis objek. Ge-Tekbol dibangun menjadi 2, aplikasi dan Gelang GeTekbol - Parent untuk pengguna orangtua dan Ge-Tekbol- Gelang untuk pengguna anak.
\end{abstract}

Kata kunci: Anak, Orangtua, Pendeteksi, Aplikasi, Tombol

\section{Abstract}

The development of the Times increasing with the number of cases of child Abductions lately and quite troubling people living in surroundings, especially parents who have children of an age average of 7-12 years and the level of SD/MI. Children who start school are already outside the scope of parents so that the rate of child abduction can happen. With the Presence of Technology. GeTekbol Detecting presence of a child with a smartphone a parent who installed the Android app and the child can sending message emergency notification when a state of urgency to the parent by pressing the button. Ge-Tekbol using technology Assisted Global Positioning System (A-GPS), determining the position on the GPS with the help of the server helpers from the cellular BTS the software is built using modeling-based objects. the app and Bracelet Ge-Tekbol - Parent to users of parental and Ge-Tekbol- bands to the user of the child.

Keywords: Child, parents, Detecting, android app, button

\section{Pendahuluan}

Anak merupakan amanah sekaligus karunia Tuhan Yang Maha Esa yang harus dijaga karena pada anak juga melekat harkat, martabat, dan hak-hak sebagai bagian dari manusia yang harus dijunjung tinggi. Realitas keadaan anak di muka bumi ini masih belum menggembirakan nasib mereka belum seindah ungkapan verbal yang kerap kali memposisikan anak sebagai sesuatu yang bernilai, penting, dan sebagai penerus masa depan bangsa dan Negara. Anak sangat rentan menjadi korban dalam suatu kejahatan (victim of crime).

Perkembangan Zaman semakin meningkat dengan banyaknya kasus-kasus Penculikan anak akhir-akhir ini dan cukup meresahkan masyakarakat khususnya orang tua yang memiliki anak yang umurnya rata-rata 7-12 tahun dan jenjang SD/MI[1]. Pada saat ajaran baru yaitu masuk sekolah. Anak yang mulai sekolah sudah diluar pantuan orang tua sehingga tingkat penculikan anak bisa saja terjadi membuka peluang oknum untuk melakukan tindakan kriminal.

Berdasarkan permasalahan di atas maka dirumuskan membuat teknologi Pendeteksi Keberadaan Anak yang dapat membuat orang tua mengetahui posisi keberadaan anak dan mudah di pakai oleh orang tua dan nyaman di gunakan oleh anak. Berdasarkan rumusan di atas maka Tujuan yang akan dicapai pada pelaksanaan ini Untuk mendeteksi keberadaan anak dengan aplikasi Android "Ge-Tekbol" Gelang Pendekteksi Keberadaan Anak dan Menggunakan Tombol Darurat, terdapat tombol darurat pada gelang berwarna merah yang pada saat digunakan dapat mengirim notifikasi sms ke smartphone Android orangtua. 
ILKOM Jurnal Ilmiah Volume 11 Nomor 2 Agustus 2019 Terakreditasi peringkat 3 SK. No. 28/E/KPT/2019

Tujuan dari teknologi ini membantu Orang tua mengetahui keberadaan sang anak, dengan prinsip kerja aplikasi Android "Ge-Tekbol" Gelang Pendeteksi Keberadaan Anak dan Menggunakan Tombol Daurat. Membuat orang tua tenang dan tidak susah mengawasi anak anaknya dimana posisi keberadaan dengan adanya kebermanfaatan aplikasi Android Ge-Tekbol Menggunakan Assisted Global Positioning System (A-GPS) merupakan pengembangan dari sistem GPS biasa sebagai penentu posisi. yang dalam penentuan posisi tidak hanya mengandalkan sinyal dari satelit gps, tetapi mendapatkan assist dari sebuah server data yaitu operator selular. Bantuan berupa data posisi yang diambil berdasarkan LBS (Location Based Service), ialah suatu sistem penentu lokasi berdasrkan BTS (Base Transceiver System). Data lokasi yang tidak hanya dikirim menggunakan satelit dibantu juga data dari server yang di sampaikan ke A-GPS melalui koneksi data via GPRS atau 3G, sehingga penentuan posisi lebih cepat atau disebut juga Time To First Fix (TTFF) dan lebih akurat berkat bantuan server data operator [2]. Tecknologi Assisted Global Positioning System (A-GPS) memperbaiki performansi GPS biasa dengan menyediakan informasi lewat kanal komunikasi alternative yang terhubung ke suatu server pembantu, dimana A-GPS receiver akan mendapatkan beberapa informasi yang biasanya diterima dari satelit melalui server tersebut. Inilah yang membedakan antara A-GPS dengan GPS, yaitu penambahan elemen assistance server atau juga disebut LBS (location Base Service) tempat yang di posisikan. Berdasarkan Tujuan diatas maka Teknologi memiliki Batasan Seperti A-GPS gelang ttitik koordinat dikonfirmasi ke BTS GSM untuk kemudian dikirim ke server melalui internet dan orang tua menerima notivikasi titik koordinat dari gelang Ge-Tekbol, Penentuan posisi pada A-GPS adalah dengan menggunakan perhitungan jarak. Jarak yang dimaksud adalah jarak antara user dan satelit GPS. Jarak ini bisa didapatkan setelah lama waktu perjalanan sinyal GPS dari mulai dikirim oleh satelit hingga diterima oleh A-GPS receiver diketahui. Sedangkan kecepatan sinyal GPS setara dengan kecepatan cahaya, yaitu 3x105 km/s . Dengan persamaan matematika $\mathrm{s}=\mathrm{v} \times \mathrm{t}$, dimana $\mathrm{s}=$ jarak, $\mathrm{v}=$ kecepatan sinyal (setara kecepatan cahaya $\mathrm{c}=3 \times 105 \mathrm{~km} / \mathrm{s}$ ), dan $\mathrm{t}=$ waktu, maka jarak antara user dan satelit GPS dapat diketahui.

\section{Metode}

Metode Studi literatur adalah tahap awal pengembangan produk yang dilakukan untuk mengetahui kebutuhan dalam proses pembuatan Ge-Tekbol Gelang Pendeteksi Keberadaan Anak dan Menggunakan Tombol. Ge-Tekbol Studi literatur yang dilakukan, yaitu studi literatur untuk menentukan komponen yang dibutuhkan dalam pembuatan pembuatan Ge-Tekbol Gelang Pendeteksi Keberadaan Anak dan Menggunakan Tombol. Tidak hanya itu, observasi kepada Anak Orang tua juga dilakukan untuk orang tua dapat mendekteksi keberadaan anak dengan smartphone yang terpasang aplikasi Android dan anak dapat menghubungi orang tua dengan menekan tombol darurat.

\subsection{Tahap Desain/Perancangan Sistem}

Pada Gambar 1 dibawah desain Ge-tekbol terdapat tombol darurat pada gelang (sos) yang pada saat digunakan dapat mengirim notifikasi sms sos ke smartphone Android orangtua[2], pada tombol darurat berwarna merah simple praktis dan mudah digunakan, wadah Ge-Tekbol dengan fiber acrylic agar lebih efektif jika mengenai air.

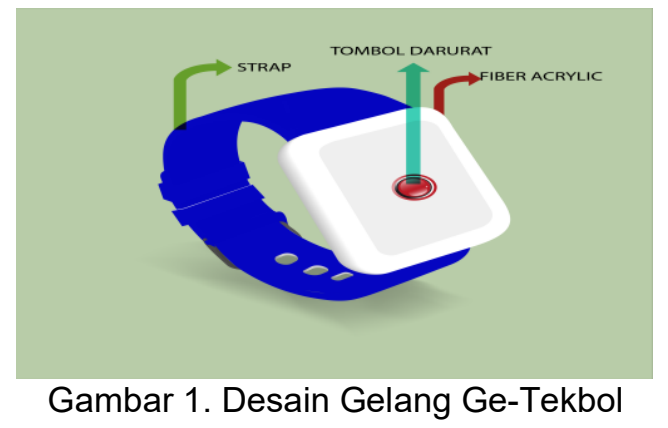

Aplikasi Ge-tekbol pada smartphone Android adalah aplikasi yang digunakan untuk mengetahui keberadaan anak, Gelang Mengirim Sinyal ke Satelit A-GPS kemudian di kembalikan AGPS gelang tersebut setelah mendapatkan titik koordinat satelit A-GPS, kemudian dikonfirmasi ke BTS GSM untuk kemudia dikirim ke server melalui internet orang tua menerima notivikasi titik koordinat dari gelang Ge-Tekbol, Aplikasi ini dapat mengetahui keberadaan anak saat berpergian dengan menggunakan gelang Ge-tekbol Selain itu juga pada gelang Ge-takbol terdapat tombol pada 
ILKOM Jurnal Ilmiah Volume 11 Nomor 2 Agustus 2019 Terakreditasi peringkat 3 SK. No. 28/E/KPT/2019

saat situasi darurat anak akan menekan tombol tersebut sehingga orang tua akan bertindak. Aplikasi ini menggunakan sebuah perangkat yaitu A-GPS[2].

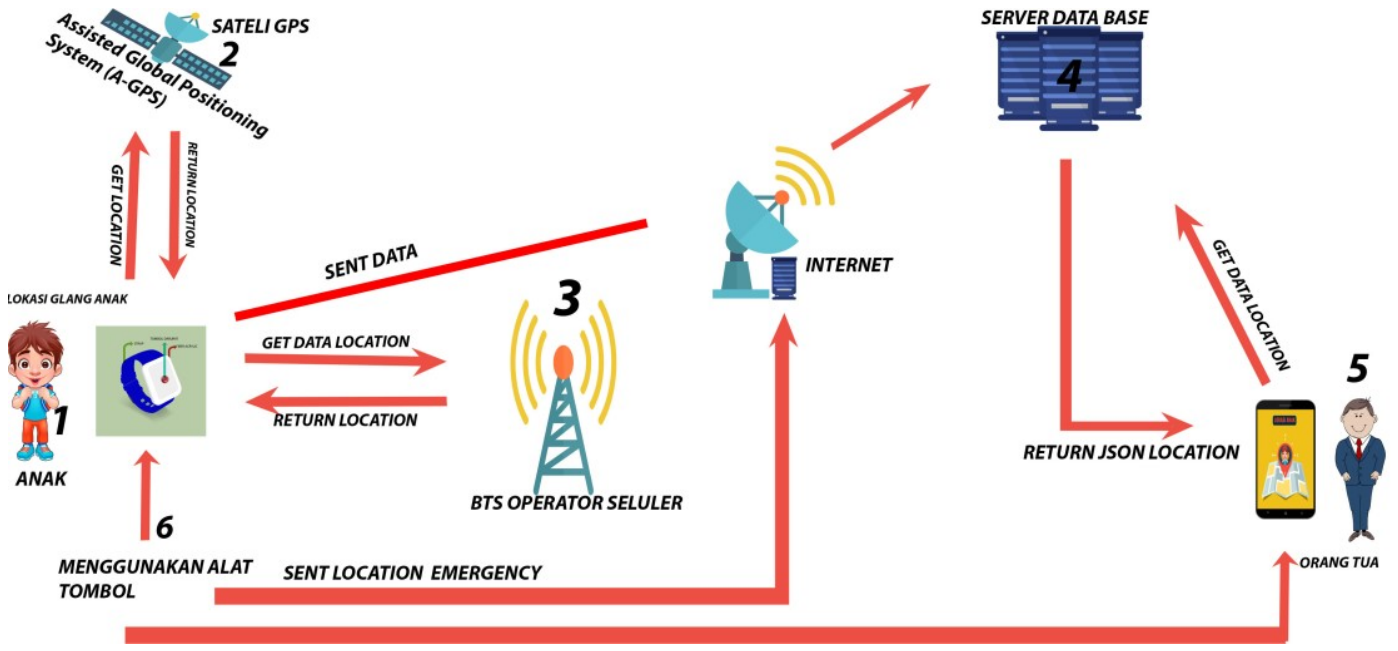

Gambar 2. Alur Sistem Ge-Tekbol

Pada Gambar 2. di atas Penentuan posisi pada A-GPS adalah dengan menggunakan perhitungan jarak. Jarak yang dimaksud adalah jarak antara user dan satelit GPS. Jarak ini bisa didapatkan setelah lama waktu perjalanan sinyal GPS dari mulai dikirim oleh satelit hingga diterima oleh A-GPS receiver diketahui. Sedangkan kecepatan sinyal GPS setara dengan kecepatan cahaya, yaitu $3 \times 105 \mathrm{~km} / \mathrm{s}$. Dengan persamaan matematika $s=v \times t$, dimana $s=$ jarak, $v=$ kecepatan sinyal (setara kecepatan cahaya $\mathrm{c}=3 \times 105 \mathrm{~km} / \mathrm{s}$ ), dan $\mathrm{t}=$ waktu, maka jarak antara user dan satelit GPS dapat diketahui.

Mengukur Jarak Dua Titik dengan Titik Koordinat Jarak merupakan selisih dari posisi awal dan posisi akhir. Pada kasus ini akan dilakukan pengukuran jarak dengan hanya mengetahui koordinat bumi yang disebut kordinat lintang dan bujur dengan menggunakan metode Euclidean. Nilai koordinat bumi yang digunakan metode Euclidean merupakan bentuk Decimal Degree yang dituliskan seperti berikut : Latitude : -5.136094 • Longitute: 119.448982

Formula Euclidean adalah sebagai berikut:

Jarak $=\sqrt{ }($ lat $2-$ Lat 1$) 2+($ long $2-$ Long 1$) 2 \times 111.319 \mathrm{Km}$

Keterangan :

Lat 1 = Latitude Referensi

Long1 $=$ Longitude Referensi

Lat2 = Pembacaan Latitude modul GPS

Long2 = Pembacaan Longitude modul GPS[3]

\subsection{Tahap Pembuatan dan Perakitan Ge-Tekbol}

Pada tahap ini dirakit Sistem elektronik dari Teknologi GPS yang menggunakan prisip assisted Global Positioning System (A-GPS). Secara garis besar terdapat 5 bagian perakitan yaitu GPS Module Neo6mv2, Arduino Promini, Module sim 800L, Lithium Battery Charging Board 1A Micro USB dan Module Tombol Darurat. GPS NEO-6M dengan Arduino untuk mendapatkan data GPS. GPS adalah singkatan dari Global Positioning System dan dapat digunakan untuk menentukan posisi, waktu, dan kecepatan jika Anda bepergian sehingga dengan modul tersebut kita dapat membuat berbagi macam alat yang memerlukan lokasi / titik koordinat[4]. dari modul tersebut kita dapat mendapatkan titik garis lintang / latitude dan garis bujur / longitude. dan dilengkapi komponen utama lainnya yaitu Arduino promini ATMEGA328P 5V 16Mhz, Module Sim 800L, Lithium Battery Charging Board 1A Micro USB, dan module Tombol[4]. 
ILKOM Jurnal IImiah Volume 11 Nomor 2 Agustus 2019 Terakreditasi peringkat 3 SK. No. 28/E/KPT/2019

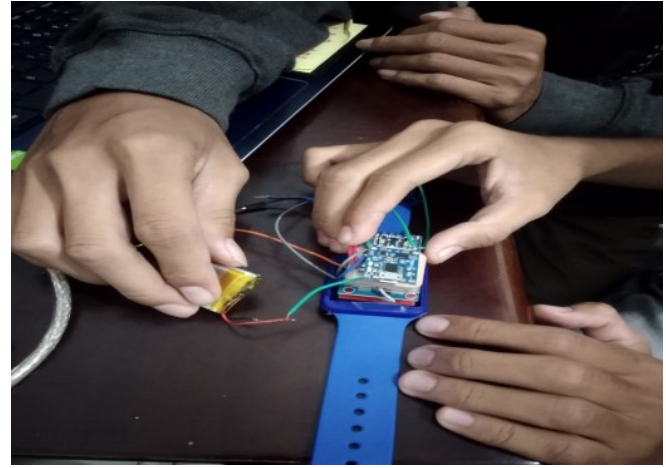

Gambar 3. Perakitan Ge-Tekol

1. Gps Ublox Neo $6 \mathrm{~m}$

Modul GPS Ublox neo-6m maka kita dapat mengetahui lokasi suatu tempat / koordinat dimana modul GPS itu berada, sehingga dengan modul tersebut kita dapat membuat berbagi macam alat yang memerlukan lokasi / titik koordinat. dari modul tersebut kita dapat mendapatkan titik garis lintang / latitude dan garis bujur / longitude [5].

2. Arduino Pro mini

Arduino Pro Mini adalah papan pengembangan (development board) mikrokontroler yang berbasis chip ATmega328P dengan bentuk yang sangat mungil dan paling minimalis. Secara fungsi tidak ada bedanya dengan Arduino Uno, dan sangat mirip dengan Arduino Nano. Perbedaan utama terletak pada ketiadaan jack power DC dan konektor Mini-B USB, sehingga harus menggunakan modul FTDI atau USB to TTL untuk menghubungkan ke komputer.

3. $\operatorname{Sim} 800 \mathrm{~L}$

Sim800L adalah GSM/GPRS module u/ uC / Arduino / Raspberry Pi. Dapat digunakan u/ mengirim sms, calling, transfer data melalui GPRS \& fungsi DTMF. SIM800L support Quadband 850/900/1800/1900MHz. Dilengkapi juga fungsi Bluetooth, FM \& Embedded AT.[6]

4. Lithium Batterai Charging

Lipo Charger $1 \mathrm{~A}$ ini adalah modul untuk mengisi baterai isi ulang Lithium (Li-ion rechargeable battery) 1 Ampere yang dilengkapi dengan 2 lampu indikator, masing-masing menunjukkan status saat mengisi ulang (charging) dan saat baterai sudah terisi penuh (fully charged). Modul ini menggunakan IC TP4056 yang merupakan IC pengisi ulang linear untuk baterai lithium-ion sel tunggal dengan arus dan tegangan yang konstan yang dilemgkapi dengan sistem pengaturan suhu (thermal regulation). Tegangan pengisian konstan di 4,2 Volt (akurasi $\pm 1,5 \%$ ), ideal untuk digunakan mengisi ulang baterai bertegangan $3 \sim 3,7$ Volt. Fitur lainnya dari IC ini adalah pemantau arus, pengunci tegangan kurang (under-voltage lockout), pengisi ulang otomatis, dan dua status pin yang mana pada modul ini dihubungkan dengan LED indikator.[7]

Pada gambar 3. Perakitan Perangkatan Keras komponen module pada kerangkah adalah :

1) Memasang GPS Module Neo6mv2 pada Gelang

2) Menempelkan Module Arduino promini ATMEGA328P 5V 16Mhz pada kerangkah prototipe Ge-Tekbol

3) Menempelkan Module Sim 800 L dan menghubungkan Lithium Battery Charging Board $1 \mathrm{~A}$ Micro USB ke kerangkah prototipe Ge-Tekbol

4) Menempelkan Module Tombol darurat di bagian atas Module

5) Menghubungkan Komponen tersebut dengan kabel yang berpusat pada Kerangkah Prototipe Ge-Tekbol

\section{Hasil dan Pembahasan}

Setelah tahapan implementasi perakitan sistem mekanis dan elektronisnya selesai, selanjutnya dilakukan pengujian kinerja alat GPS hingga sistem berkerja sempurna seperti yang direncanakan. Untuk menguji kelayakan GE-Tekbol Gelang Pendeteksi Keberadaan Anak dan Menggunakan Tombol Darurat dilakukan pada GPS, pada gelang Assisted Global Positioning System (A-GPS) 
ILKOM Jurnal Ilmiah Volume 11 Nomor 2 Agustus 2019 Terakreditasi peringkat 3 SK. No. 28/E/KPT/2019

memperbaiki performasi GPS yang terhubung ke suatu server pembantu, sehingga fungsi dari GPS pada gelang untuk mendeteksi keberadaan anak dapat berfungsi dengan baik[2].

Tahapan Pengujian Terhadap aplikasi Cara Kerja Pada Gambar 4. Merupakan Cara Penggunaan aplikasi ini terdapat beberapa fitur umum seperti masuk, registrasi serta dashboard utama. Terdapat menu Pengisian Nama, Nomor Ge-Tekbol dan Password, Nama tersebut di isikan nama anak, nomor telepon pada gelang Ge-tekbol Untuk notifikasikan pada aplikasi dan passwoard aplikasi, Selain itu "Ge-Tekbol" juga memiliki maps dan list enter untuk menampilkan lokasi anak, terdapat tombol darurat pada gelang berwarna merah yang pada saat digunakan dapat mengirim notifikasi sms ke smartphone Android Mobile orangtua, notifikasi ke smartphone ke orang tua akan bergetar terus hingga orang tua mengecek sms tersebut.

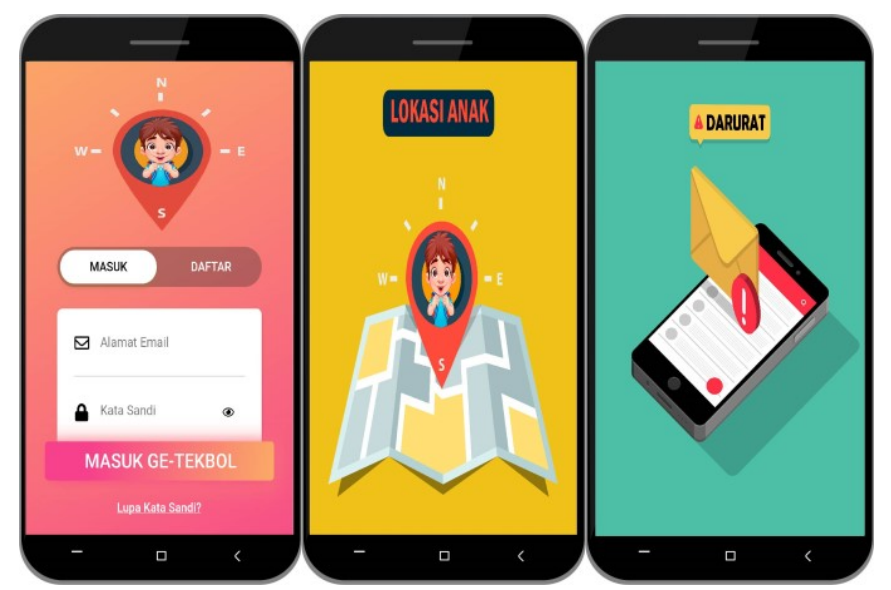

Gambar 4. Aplikasi Ge-Tekbol

\section{Kesimpulan dan Saran}

Berdasarkan dari hasil pembuatan dan pembahasan yang dilakukan maka diperoleh kesimpulan bahwa Ge-Tekbol Gelang Pendeteksi Keberadaan anak dan Menggunakan Tombol Darurat yaitu dengan adanya aplikasi Ge-Tekbol pada platform android, orangtua dapat dengan mudah mengetahui keberadaan anak secara jarak jauh dengan hanya menggunakan Aplikasi Android. Aplikasi Ge-Tekbol pada platform android membantu anak menghubungi orangtua dengan cepat melalui fitur sos yang pada saat digunakan dapat mengirim notifikasi sos ke smartphone orangtua akan terus muncul hingga orang tua melihat pesan tersebut secara otomatis setelah beberapa detik tombol sos di gunakan. Pengembangan aplikasi ini maka dapat menambah fitur lain saat penanganan jika aplikasi Ge-Tekbol sedang tidak ada internet tetapi tetap dapat mengirimkan lokasi kepada orangtua. Memperbaiki tampilan aplikasi sehingga dapat lebih menarik. Mengembangkan platform yang dapat didukung oleh perangkat lunak mengingat saat ini hanya mendukung pada platform android.

5. Ucapan Terima Kasih

Terima kasih kepada Direktorat Jenderal Pembelajaran dan Kemahasiswa (Ditjen Balmawa) Riset Dikti atas dana pada kegiatan Program Kreativitas Mahasiswa Karsa Cipta (PKM-KC) tahun 2019

\section{Daftar Pustaka}

[1] Gustian, Edy. Mempersiapan Anak Masuk Sekolah. Jakarta: Puspa Swara.2001

[2] D. Muhammad, N. M. A., ST., MT. and T. A. W., ST., MT., "Analisis Performansi Mobile Tracking Berbasis Sistem Seluler dengan Metode A-GPS," p. 11, 2012.

[3] Gusmanto, Marindani, E. Sanjaya, B. Rancang Bangun Sistem Peringatan Dini Dan Pelacakan Pada Kendaraan Sepeda Motor Dengan Menggunakan Mikrokontroler Arduino Nano. Jurnal Teknik Elektro Universitas Tanjungpura. Volume (2):2-3, 2016

[4] Hermono, I. Rusdinar, A. Ramdhani, M..Security Car System Based Gps And Sms. eProceeding of Applied Science. Volume (1):2616-2619, 2015

[5] U-blox, NEO-6M Datasheet [Online]. Availabe : https://www2.ublox.com/images/downloads/Product_Docs/NEO-6_DataSheet_(GPS.G6-HW-09005).pdf 
ILKOM Jurnal Ilmiah Volume 11 Nomor 2 Agustus 2019

Terakreditasi peringkat 3 SK. No. $28 /$ E/KPT/2019

[Accessed 24 juli 2018]

[6] Kadir, Abdul. 2013. Panduan Praktis Mempelajari Aplikasi Mikrokontroller dan Pemograman Arduino. Yogyakarta : Penerbit Andi

[7] Widodo, R. B. 2011. Embeded system menggunakan Mikrokontroller dan pemograman C. Yogyakarta : Penerbit And 